\title{
Effect of Microwave Irradiation on the Catalytic Activity of Palladium Supported Catalysts in the One-Step Isomerisation of Cinchona Alkaloids to $\Delta^{3,10}$-Isobases
}

\author{
Teodozja M. Lipińska ${ }^{1}$ Dominika Borowska ${ }^{1}$ Natalia Swędra ${ }^{1}$. \\ Katarzyna Trochim ${ }^{1}$
}

Received: 7 April 2017 / Accepted: 10 August 2017 / Published online: 7 September 2017

(c) The Author(s) 2017. This article is an open access publication

\begin{abstract}
Efficiency of palladium solid supported (Pd/SS) catalysts for one-step isomerisation of the side chain of four natural Cinchona alkaloids have been explored under controlled microwave heating in the green media (50\% aqueous ethanol or ethylene glycol with $\mathrm{HCl}$ ). Conversion progress and products purity was monitored by TLC and by ${ }^{1} \mathrm{H}$ NMR spectrometry. Final conversion is dependent on the support $\left(\mathrm{Al}_{2} \mathrm{O}_{3}, \mathrm{C}\right.$ or $\left.\mathrm{BaSO}_{4}\right)$, reaction time and temperature. Very good results: high yields and purity of (Z/E) $\Delta^{3,10}$-isomers were obtained from quinine and quinidine with $10 \% \mathrm{Pd} /$ $\mathrm{BaSO}_{4}$ as the catalyst, which is less effective for isomerisation of cinchonine and cinchonidine. Enhancing energy efficiency can be possible when the responsive support selective absorbs of microwave energy, which is translated to the palladium giving acceleration of the formation and disintegration of the transition state leading to $\Delta^{3,10}$-isomers.
\end{abstract}

Electronic supplementary material The online version of this article (doi:10.1007/s10562-017-2169-3) contains supplementary material, which is available to authorized users.

Teodozja M. Lipińska

tlip@uph.edu.pl

1 Faculty of Sciences, Institute of Chemistry, Siedlce University of Natural Sciences and Humanities, ul 3 Maja 54, 08-110 Siedlce, Poland

\section{Graphical Abstract}

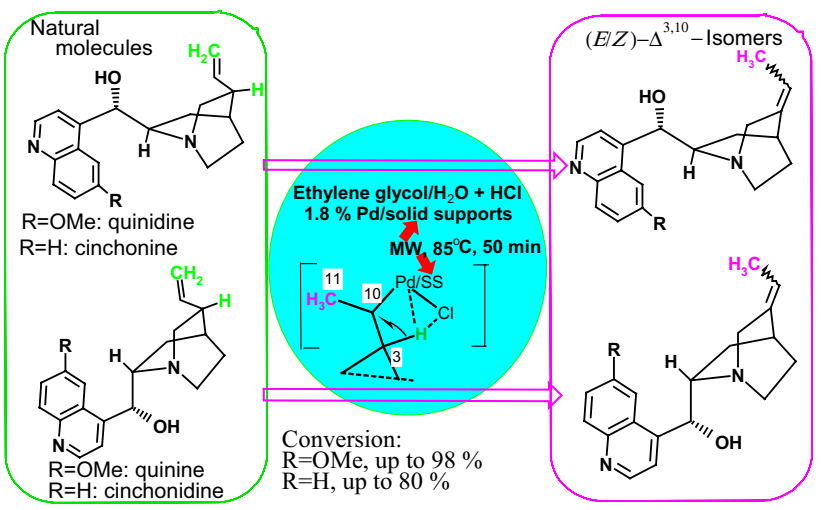

Keywords Heterogeneous catalysis - Alkene isomerisation - Cinchona alkaloids modification . Metal-solid support-interaction under microwaves . Chemoselectivity · Green methodology

\section{Introduction}

The vinyl side chain plays an important role in the structure of natural molecules of Cinchona alkaloids [1, 2]. It is a stereo-differentiating element [3] imparting a variety their physicochemical properties and biological activity for quinidine 1a (antiarrhythmic agent) [4] versus quinine 2a (antimalarial activity) [5], and for cinchonine $\mathbf{1 b}$ versus cinchonidine $\mathbf{2 b}$. All the four natural compounds, their derivatives and metal complexes have become more and more interesting catalysts for asymmetric syntheses [6]. Recently they play an important role in the preparation of new chiral nanomaterials $[7,8]$. 
The Cinchona $\Delta^{3,10}$-isomers 3a,b and $\mathbf{4 a}, \mathbf{b}$ (Scheme 1) were investigated as effective chiral modifiers of solid-supported metallic catalysts for enantioselective hydrogenation of activated ketones [9-11]. $\Delta^{3,10}$-Isobases were applied also as valuable intermediates for modification of the native structure [12] including the oxidative cleavage of the double bond [13-16].

The isomerisation of the vinyl bond to the 3,10 position of Cinchona alkaloid molecules has been investigated for more than 100 years [17]. At the beginning, $\mathrm{H}_{2} \mathrm{SO}_{4}$ has been used, which resulted in many side processes such as the cleavage of methyl ethers in molecules 1a and 2a giving phenols. It was necessary to use of diazomethane for etherification $[18,19]$. Two-step synthesis of the $\Delta^{3,10}$-isobases $\mathbf{3 a}, \mathbf{b}$ and $\mathbf{4 a}, \mathbf{b}$, consisting of hydrogen halide addition and subsequent elimination by different bases has been elaborated [14-16, 20, 21]. However this way cannot be considered today as a modern preparative method by reason of poor atom economy, which is even poorer when additional stages of protection-deprotection of the hydroxy group must be performed [13, 14] for prevention of the formation of isomers possessing an intramolecular ether bond between C9 and C10.

In 1968 it was discovered that migration of double bond in natural quinidine and quinine $\mathbf{1 a}$ and $\mathbf{1 b}$ occurs during their commercial hydrogenation with Pd-C catalyst and furthermore that $\Delta^{3,10}$-isomers $\mathbf{3 a}$ and $\mathbf{4 a}$ are resistant to subsequent hydrogenation [22]. The effective isomerisation of methoxy alkaloids 1a and 2a to (Z/E)-3a and (Z/E)-4a was performed using rhodium solid supported catalysts $(\mathrm{Rh} / \mathrm{SS})$ in a medium of $50 \% \mathrm{EtOH}$ in the presence of $\mathrm{HCl}$ under heating in water bath for a period of $24 \mathrm{~h}$ [23]. However, very low activity of palladium supported catalysts $(\mathrm{Pd} / \mathrm{SS})$ has been noted in this conditions. In 2005 ruthenium (III)

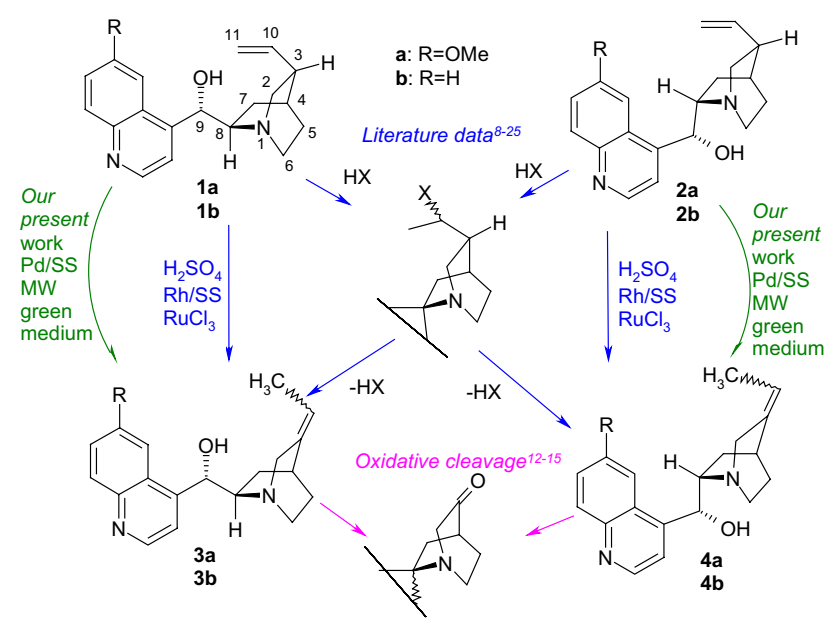

Scheme 1 Modes of transformations of the natural Cinchona alkaloids $\mathbf{1 a}, \mathbf{b}, \mathbf{2 a}, \mathbf{b}$ into the $\Delta^{3,10}$-isobases $\mathbf{3 a}, \mathbf{b}, \mathbf{4 a}, \mathbf{b}$ chloride trihydrate was used with addition of $\mathrm{H}_{2} \mathrm{SO}_{4}$ in ethanol for homogeneous quinine isomerisation [12]. Both those catalysts are expensive and cannot be used for large scale processes.

Microwave enhancement of many catalytic syntheses has been described [24-26]. Recently are described transformations of polar organic molecules in water with enhancing energy efficiency by microwaves with core/shell catalysts [27]. The heat generated at the core area of the support by microwave irradiation can be translated to the shell catalyst directly. Such localized heating allows maximum heat utilization and enhances the energy efficiency of catalytic reaction.

We have established that the difficult Fischer indole synthesis can be accelerated by microwaves together with using green reagents: catalytic amounts of $\mathrm{ZnCl}_{2}$ loaded on $\mathrm{K} 10$ clay [28] or dissolved in triethylene glycol [29]. We have recently described the results of our research on relationship structure-reactivity of natural Cinchona alkaloids $O$-tosyl derivatives in hydrolysis to 9 -epibases. We found that replacement of conventional heating with microwave activation leads to different products [30, 31].

Our present synthetic interest concentrates on finding an effective and cheap method of transformation of four Cinchona alkaloids $\mathbf{1 a}, \mathbf{b}$ and $\mathbf{2 a}, \mathbf{b}$ into the corresponding $\Delta^{3,10}$-isobases 3a,b and $\mathbf{4 a}, \mathbf{b}$. We envisioned that heating of substrates under microwaves with palladium on solid supports $(\mathrm{Pd} / \mathrm{SS})$ together with $\mathrm{HCl}$ can solve this problem. This paper described our work on influence of controlled microwave heating on activity of palladium solid supported $(\mathrm{Pd} / \mathrm{SS})$ catalysts in the heterogeneous isomerisation of four natural Cinchona alkaloids. We studied also possibility of analysis and isolation of the geometric isomers $\mathrm{Z}$ and $\mathrm{E}$ in $\Delta^{3,10}$-isomers, as they will be used as chiral ligands $[7,8]$, catalysts and modifiers in asymmetric syntheses [9-12].

\section{Results and Discussion}

Four commercial Cinchona alkaloids 1a,b, 2a,b were subjected to catalytic isomerisation of the side chain using tested palladium catalysts supported on various solids. We applied microwave activation instead conventional heating in water bath. Two methods regarding to reaction medium and temperature were used: method 1 -controlled microwave heating at $70{ }^{\circ} \mathrm{C}$ in an aqueous ethanol [31] and method 2-heating at $85{ }^{\circ} \mathrm{C}$ in a medium of ethylene glycol (EG).

Our initial small-scale experiments under controlled microwave heating were performed with $0.5 \mathrm{mmol}$ of the substrate 1a or $2 \mathbf{a}$ at $70{ }^{\circ} \mathrm{C}$ in a medium comprised of $50 \%$ EtOH with $\mathrm{HCl}$ aq in the presence of catalytic amount (1.8\%) of $10 \%$ palladium loaded on various solid supports (method 1). This procedure was tested to find the optimal 
time for conversion of 1a or 2a to the isomers $(Z / E)$-3a or $(Z / E)-\mathbf{4 a}$. We monitored the ongoing conversion progress of substrates by taking micro-samples of the reaction mixture regularly, at 10-min intervals, which after extraction with diethyl ether in the presence of aqueous ammonia were analyzed by TLC (silica gel plates, methoxyethanol). The $R_{f}$ values of the products $3 \mathbf{a}$ and $\mathbf{4 a}$ are higher than the $R_{f}$ values of the substrates 1a and 2a (see Table 3 ). The reaction mixtures were irradiated for $30 \mathrm{~min}$ or after $50 \mathrm{~min}$. After this times crude products were isolated and qualitatively and quantitatively analysed by ${ }^{1} \mathrm{H}$ NMR spectroscopy (Table 1 ).
Analysis of ${ }^{1} \mathrm{H}$ NMR spectra give the possibility to estimate the amount of product and unconverted substrate and also ratio $(Z)$ to $(E)$ isomers in the crude product for each experimental entry. The region of $6.10-4.00 \mathrm{ppm}$ in the ${ }^{1} \mathrm{H}$ NMR spectra is useful for relative amount of components determination as is shown in the Fig. 1. The alkene protons of $=\mathrm{HC}-\mathrm{Me}$ from $(Z)$ - and $(E)-\Delta^{3,10}$-isomers give two separate signals according to the literature data [12, 13, 25]. Determination of unconverted substrates can be possible from integration of peaks: $=\mathrm{CH}_{2}$ protons (two doublets at $\sim 4.90-5.10 \mathrm{ppm}$ ) or $-\mathrm{CH}=$ (multiplet at $\sim 6.00 \mathrm{ppm}$ ).
Table 1 Results of microwavepromoted isomerisation of quinidine $1 \mathbf{a}$ and quinine $\mathbf{2 a}$ into 3a and $\mathbf{4 a}$ (Scheme 2) with palladium supported catalysts in $50 \%$ aqueous ethanol in the presence of $\mathrm{HCl}$ at the controlled temperature $70{ }^{\circ} \mathrm{C}$ $(\operatorname{method} 1)$
Scheme 2 One-pot isomerisation of the side chain with palladium supported catalysts under microwave activation

\begin{tabular}{llllllll}
\hline Entry & Substrate & Catalyst & Time $(\mathrm{min})$ & Product & Yield $\left.{ }^{\mathrm{a}} \%\right)$ & $\begin{array}{l}\text { Conver- } \\
\text { sion }^{\mathrm{b}}(\%)\end{array}$ & $\begin{array}{l}\text { The } Z / E \text { ratio in } \\
\text { crude products }\end{array}$ \\
\hline 1 & $\mathbf{1 a}$ & $\mathrm{Pd} / \mathrm{Al}_{2} \mathrm{O}_{3}$ & 30 & $(Z / E)-\mathbf{3 a}$ & 95 & 80 & 7.0 \\
2 & $\mathbf{1 a}$ & $\mathrm{Pd} / \mathrm{Al}_{2} \mathrm{O}_{3}$ & 50 & $(Z / E)-\mathbf{3 a}$ & 95 & 85 & 4.7 \\
3 & $\mathbf{2 a}$ & $\mathrm{Pd} / \mathrm{Al}_{2} \mathrm{O}_{3}$ & 30 & $(Z / E)-\mathbf{4 a}$ & 98 & 70 & 1.8 \\
4 & $\mathbf{2 a}$ & $\mathrm{Pd} / \mathrm{Al}_{2} \mathrm{O}_{3}$ & 50 & $(Z / E)-\mathbf{4 a}$ & 98 & 72 & 1.6 \\
5 & $\mathbf{1 a}$ & $\mathrm{Pd} / \mathrm{C}$ & 30 & $(Z / E)-\mathbf{3 a}$ & 75 & 70 & 2.7 \\
6 & $\mathbf{1 a}$ & $\mathrm{Pd} / \mathrm{C}$ & 50 & $(Z / E)-\mathbf{3 a}$ & 75 & 75 & 2.7 \\
7 & $\mathbf{2 a}$ & $\mathrm{Pd} / \mathrm{C}$ & 30 & $(Z / E)-\mathbf{4 a}$ & 65 & 60 & 1.4 \\
8 & $\mathbf{2 a}$ & $\mathrm{Pd} / \mathrm{C}$ & 50 & $(Z / E)-\mathbf{4 a}$ & 60 & 65 & 1.4 \\
9 & $\mathbf{1 a}$ & $\mathrm{Pd} / \mathrm{BaSO}_{4}$ & 30 & $(Z / E)-\mathbf{3 a}$ & 96 & 87 & 6.3 \\
10 & $\mathbf{1 a}$ & $\mathrm{Pd} / \mathrm{BaSO}_{4}$ & 50 & $(Z / E)-\mathbf{3 a}$ & 96 & 94 & 5.7 \\
11 & $\mathbf{2 a}$ & $\mathrm{Pd} / \mathrm{BaSO}_{4}$ & 30 & $(Z / E)-\mathbf{4 a}$ & 97 & 80 & 3.0 \\
12 & $\mathbf{2 a}$ & $\mathrm{Pd} / \mathrm{BaSO}_{4}$ & 50 & $(Z / E)-\mathbf{4 a}$ & 97 & 91 & 2.6 \\
\hline
\end{tabular}

${ }^{\mathrm{a}}$ Isolated yields of crude product $\mathbf{3 a}$ or $\mathbf{4 a}$ from the reaction mixture

${ }^{\mathrm{b}}$ Determined conversion of $\mathbf{1 a}$ or $\mathbf{2 a}$ into $\mathbf{3 a}$ or $\mathbf{4 a}$ and their $Z / E$ ratio from ${ }^{1} \mathrm{H}$ NMR spectra of crude products 
a1)' Entry 1, Table 1
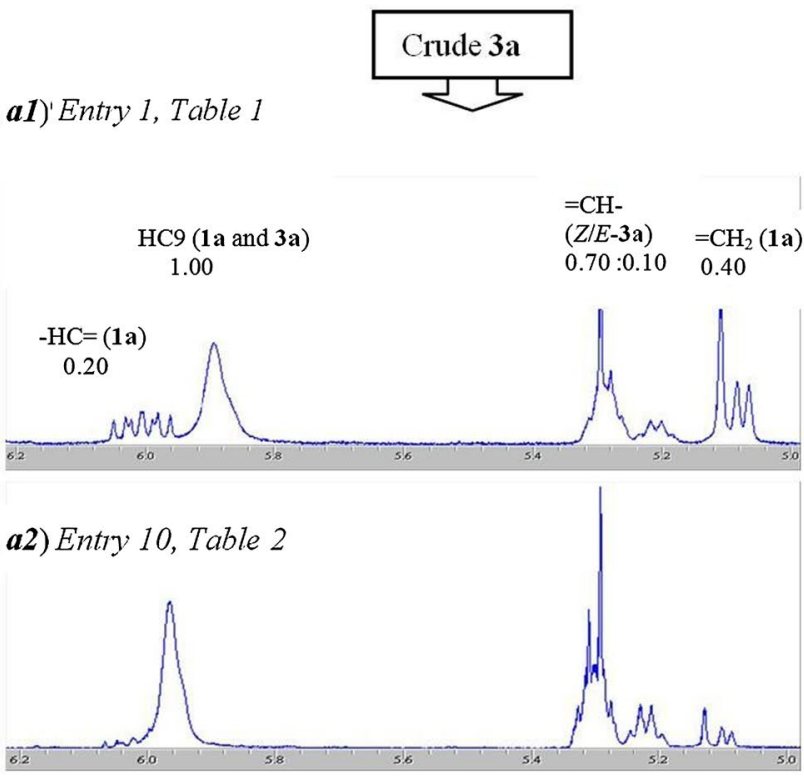

Fig. 1 Examples of fragments of ${ }^{1} \mathrm{H}$ NMR spectra (6.20-4.80 ppm) used for determination of the $Z / E$ ratio in $\Delta^{3-10}$-isomers 3a, 4a and for analysis of their contamination by unconverted substrates 1a or

The example presented in Fig. 1-a1 shows the analytical methodology for determination of the amounts of components in the crude 3a from entry 1, Table 1 (ESM Fig. S1). The signal of the alkene proton of the isomer $(Z)-\mathbf{3 a}$ appears as a multiplet at $5.30 \mathrm{ppm}$ (integration 0.70 ) whereas the signal of the isomer $(E)-3 \mathrm{a}$ is showed as a quartet at $5.33 \mathrm{ppm}$ (integration 0.10) but two protons of the $=\mathrm{CH}_{2}$ group from the unconverted substrate 1a give two doublets in the region of 5.13-5.03 ppm (integration 0.40). The comparative integration of the relevant signals give the ratio of $(\mathrm{Z})-3 \mathbf{a} /(\mathrm{E})-\mathbf{3 a} /$ unconverted substrate 1a which is 70:10:20. The conversion progress of $80 \%$ can also be inferred from the comparative integration of HC9 proton signal summed for the substrate $\mathbf{1 a}$ and the products $(Z / E)-\mathbf{3 a}$ at $5.90 \mathrm{ppm}$ (integration 1.00) and the signal of $-\mathrm{CH}=$ proton of the vinyl group of $\mathbf{1 a}$, which gives a multiplet (ddd) at 6.06-5.94 ppm (integration as 0.2 ).

The conversions of $\mathbf{2 a}$ to $(Z / E)-\mathbf{4 a}$ in our tested reactions were determined from the ${ }^{1} \mathrm{H}$ NMR spectra of the crude products as shown in Fig. 1-b1. The conversion in entry 4, Table 1 (see also Fig. S4 in SWM) was determined by comparison of integrations of two doublets of two protons of the $=\mathrm{CH}_{2}$ group of $\mathbf{2 a}$ and the summed signals of one alkene proton of $(Z / E)-\mathbf{4 a}$ isomers. Analysis of the region revealed that the crude product contains $28 \%$ of unconverted substrate 2a together with $(Z)-\mathbf{4 a}+(E)-\mathbf{4 a}$ in the ratio 1,6 . We can see from Table 1 that in method 1 the best conversion for quinidine 1a into (Z/E)-3a is $94 \%$ (entry 10 ) and for quinine 2a into (Z/E)-4a is $91 \%$ (entry 12 ) with the $\mathrm{Pd} / \mathrm{BaSO}_{4}$ catalyst when the irradiation time is prolonged to $50 \mathrm{~min}$.

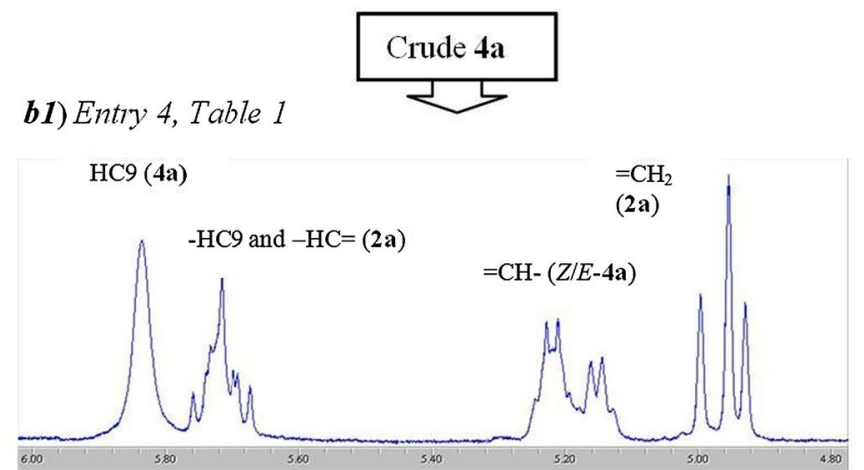

b2) Entry 12, Table 2

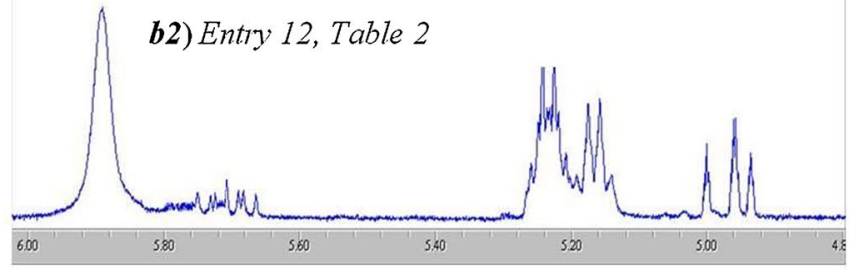

2a: crude 3a: a1 (see Fig. S1 in Supplementary Materials-SM); a2 (see Fig. S3 in SM); crude 4a: b1 (see Fig. S4 in SM); b2 (see Fig. S6 in SM)

We wanted to maximise yields of $\Delta^{3,10}$-isomers $(Z / E)$ 3a and $(Z / E)-4 a$ by adopting higher temperature $\left(85^{\circ} \mathrm{C}\right)$ and changing the reaction medium to $50 \%$ aqueous ethylene glycol (method 2, Table 2). In the case of two catalysts, $\mathrm{Pd} / \mathrm{Al}_{2} \mathrm{O}_{3}$ and $\mathrm{Pd} / \mathrm{SO}_{4}$ (entries 1-4 and 9-12, Table 2), an increased conversion of substrates $1 \mathbf{a}$ and $\mathbf{2 a}$ to the $\Delta^{3,10}$ isomers (Z/E)-3a and (Z/E)-4a was observed in comparison to method 1, (Table 1). However, in the reactions catalysed by the $\mathrm{Pd} / \mathrm{C}$ catalyst, the conversion to both $\Delta^{3,10}$-isomers was lower in method 2 (entries 5-8, Table 2 ) in comparison to method 1 (entries 5-8, Table 1).

The differences of results obtained in both methods (method 1 and method 2) is visible by comparison of the diagnostic regions of ${ }^{1} \mathrm{H}$ NMR spectra of the crude product 3a and 4a. Figure 1-a2 (see also Fig. S3 in SM) shows the ${ }^{1} \mathrm{H}$ NMR spectrum of the most pure (Z/E)-3a and Fig. 1-b2 (see also Fig. S6 in SM) presents of the best crude product (Z/E)-4a (entry 12, Table 2).

We noted that the microwave promotion of vinyl bond isomerisation in both alkaloids, quinidine 1a and quinine 2a, is less selective at temperatures higher than $85^{\circ} \mathrm{C}$. Irradiation of the reaction mixture at $100{ }^{\circ} \mathrm{C}$ in ethylene glycol leads to the cleavage of the quinuclidine ring giving quinotoxine (quinicine). The process of the high-temperature cleavage of Cinchona alkaloids in acidic medium is well known and is described in the literature as Pasteur rearrangement [1, 17].

It is interesting to note that only traces of isomerisation products $(Z / E)-\mathbf{3 a}$ or $(Z / E)$-4a were formed in experiments conducted with palladium solid supported catalysts: 
Table 2 Results of microwavepromoted isomerisation of quinidine $\mathbf{1 a}$ and quinine $\mathbf{2 a}$ into 3a and $\mathbf{4 a}$ (Scheme 2) in $50 \%$ aqueous ethylene glycol in the presence of $\mathrm{HCl}$ at the controlled temperature $85^{\circ} \mathrm{C}$ (method 2)

\begin{tabular}{llllllll}
\hline Entry & Substrate & Catalyst & Time $(\mathrm{min})$ & Product & Yield $^{\mathrm{a}}(\%)$ & $\begin{array}{l}\text { Conver- } \\
\text { sion }^{\mathrm{b}}(\%)\end{array}$ & $\begin{array}{l}\text { The } Z / E \text { ratio in } \\
\text { crude products }\end{array}$ \\
\hline 1 & $\mathbf{1 a}$ & $\mathrm{Pd} / \mathrm{Al}_{2} \mathrm{O}_{3}$ & 30 & $(Z / E)-\mathbf{3 a}$ & 92 & 87 & 3.4 \\
2 & $\mathbf{1 a}$ & $\mathrm{Pd} / \mathrm{Al}_{2} \mathrm{O}_{3}$ & 50 & $(Z / E)-\mathbf{3 a}$ & 90 & 90 & 5.0 \\
3 & $\mathbf{2 a}$ & $\mathrm{Pd} / \mathrm{Al}_{2} \mathrm{O}_{3}$ & 30 & $(Z / E)-\mathbf{4 a}$ & 93 & 75 & 1.5 \\
4 & $\mathbf{2 a}$ & $\mathrm{Pd} / \mathrm{Al}_{2} \mathrm{O}_{3}$ & 50 & $(Z / E)-\mathbf{4 a}$ & 91 & 80 & 1.5 \\
5 & $\mathbf{1 a}$ & $\mathrm{Pd} / \mathrm{C}$ & 30 & $(Z / E)-\mathbf{3 a}$ & 75 & 60 & 2.0 \\
6 & $\mathbf{1 a}$ & $\mathrm{Pd} / \mathrm{C}$ & 50 & $(Z / E)-\mathbf{3 a}$ & 74 & 70 & 6.0 \\
7 & $\mathbf{2 a}$ & $\mathrm{Pd} / \mathrm{C}$ & 30 & $(Z / E)-\mathbf{4 a}$ & 78 & 60 & 2.0 \\
8 & $\mathbf{2 a}$ & $\mathrm{Pd} / \mathrm{C}$ & 50 & $(Z / E)-\mathbf{4 a}$ & 80 & 56 & 2.3 \\
9 & $\mathbf{1 a}$ & $\mathrm{Pd} / \mathrm{BaSO}_{4}$ & 30 & $(Z / E)-\mathbf{3 a}$ & 95 & 95 & 3.8 \\
10 & $\mathbf{1 a}$ & $\mathrm{Pd} / \mathrm{BaSO}_{4}$ & 50 & $(Z / E)-\mathbf{3 a}$ & $\mathbf{9 6}$ & $\mathbf{9 8}$ & 3.9 \\
11 & $\mathbf{2 a}$ & $\mathrm{Pd} / \mathrm{BaSO}_{4}$ & 30 & $(Z / E)-\mathbf{4 a}$ & 94 & 90 & 1.6 \\
12 & $\mathbf{2 a}$ & $\mathrm{Pd} / \mathrm{BaSO}_{4}$ & 50 & $(Z / E)-\mathbf{4 a}$ & $\mathbf{9 5}$ & $\mathbf{9 6}$ & 1.7 \\
\hline
\end{tabular}

${ }^{a}$ Isolated yields of crude product $\mathbf{3 a}$ or $\mathbf{4 a}$ from the reaction mixture

${ }^{b}$ Determined conversion of $1 \mathbf{a}$ or $\mathbf{2 a}$ into $3 \mathbf{a}$ or $\mathbf{4 a}$ and their $Z / E$ ratio from ${ }^{1} \mathrm{H}$ NMR spectra of crude products

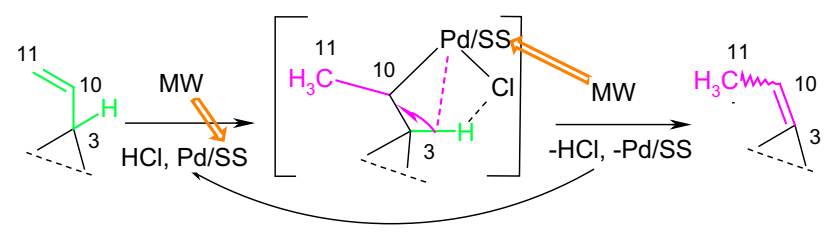

Scheme 3 Plausible mechanism of positional isomerisation of the vinyl bond in the Cinchona alkaloid molecules

a. with the use of conventional heating instead of microwave irradiation in the same reaction medium, temperature and time prolonged to $24 \mathrm{~h}$ as indicated in the literature [23].

b. when the alkaloids 1a or $\mathbf{2 a}$ were irradiated without hydrochloric acid with all the catalysts investigated at $70-90{ }^{\circ} \mathrm{C}$ for $50 \mathrm{~min}$ in $\mathrm{EtOH} / \mathrm{H}_{2} \mathrm{O}$ and also in $\mathrm{EG} / \mathrm{H}_{2} \mathrm{O}$.

The above described results mean that hydrochloric acid not only facilitate perfect solubility of the basic reactants in the reaction mixture but also acts together with palladium leading proton addition to $\mathrm{H}_{2} \mathrm{C}^{11}=$ and elimination from $\mathrm{HC}^{3}$ giving positional isomerisation of the double bond (Scheme 3).

The effect of the best microwave activation of the isomerisation process of $\mathbf{1 a}$ and $\mathbf{2 a}$ catalysed by palladium loaded on very polar $\mathrm{BaSO}_{4}$ can mean that the support selectively adsorbs microwave energy, which is translated to the palladium giving acceleration of the formation and disintegration of the transition state leading to more stable $\Delta^{3,10}$-isomers.

To expand the range of substrates, two effective catalysts, $\mathrm{Pd} / \mathrm{Al}_{2} \mathrm{O}_{3}$ and $\mathrm{Pd} / \mathrm{BaSO}_{4}$, were evaluated in the microwaveaccelerated one-step isomerisation of the double bond in the molecules of cinchonine $\mathbf{1 b}$ and cinchonidine $\mathbf{2 b}$ by method 2 . We found out that the full conversion to the appropriate $\Delta^{3,10}$-isomers $\mathbf{3 b}$ and $\mathbf{4 b}$ cannot be achieved for any combination of catalyst and time. For these alkaloids the best results were obtained with $\mathrm{Pd} / \mathrm{Al}_{2} \mathrm{O}_{3}$ catalyst. That fact can be regarded as the difference in energy of the transition state in the isomerisation process of each of alkaloids. The crude product $\mathbf{3 b}$ was formed as a mixture of $\Delta^{3,10}$-isomers $(Z)$-3b and $(E)-3 \mathbf{b}$ in a ratio of 2.5 containing $20 \%$ of unconverted 1b. The crude product $4 \mathbf{b}$ was prepared from $2 \mathbf{b}$ as a mixture of the $(Z / E) \Delta^{3,10}$-isomers in a ratio of 2.0 with high contamination $(33 \%)$ of unconverted $\mathbf{2 b}$. These data were found from the ${ }^{1} \mathrm{H}$ NMR spectra, which can be seen on Figs. $\mathrm{S} 7$ and $\mathrm{S} 9$ in SM.

Having at hand the optimized protocol, we performed microwave-promoted syntheses in the scale of $10 \mathrm{mmol}$ [32]. The reaction scale is limited due to the microwave apparatus used in the research. The results were compatible with those obtained in analytical quantities. We checked out that the purification of the crude products $\mathbf{3 a}, \mathbf{b}$ and $\mathbf{4 a}, \mathbf{b}$ can be achieved by careful recrystallization with aqueous ethanol, which accomplishes separation of starting materials. However, the ratio of the geometric isomers in the recrystallized products is not reproductible and depends on dilution of ethanol and time of cooling.

Pure $\Delta^{3,10}$-isobases $\mathbf{3 a}, \mathbf{b}$ and $\mathbf{4 a}, \mathbf{b}$ can be isolated by column chromatography because they have the lowest polarity (the highest $R_{f}$ values, see Table 3 ) in comparison to the $R_{f}$ values of the starting alkaloids 1a,b and 2a,b. We isolated the mixture of geometric isomers: $(Z / E)-\mathbf{3 a}$ in the ratio of four from crude $3 \mathbf{a}$ in $88.0 \%$ yield. The $\Delta^{3,10}$-isocinchonine has been separated in yield of $55.0 \%$ as the $(Z / E)-3 \mathbf{b}$ in a ratio 4.5. 
Table 3 Values of $R_{f}$ on silica gel TLC plates of the substrates 1a,b, 2a,b and main products $\mathbf{3 a}, \mathbf{b}, \mathbf{4 a}, \mathbf{b}$ together with their yields and the ratio of components of $Z / E$ geometric isomers

\begin{tabular}{|c|c|c|}
\hline Substrate $/ R_{f}^{\mathrm{a}}$ & $\Delta^{3,10}$-Isomer $/ R_{f}^{\mathrm{a}}$ & Yield $^{\mathrm{b}}$ of product and its component ${ }^{\mathrm{c}}$ \\
\hline Quinidine 1a: 0.44 & $(Z / E)-3 \mathbf{a}: 0.65$ & $80 \%: Z / E=4.0$ \\
\hline Cinchonine 1b: 0.41 & $(Z / E)-3 \mathbf{b}: 0.56$ & $55 \%: Z / E=4.5$ \\
\hline Quinnie 2a: 0.42 & $(Z)-\mathbf{4 a :} 0.63$ and $(E)-\mathbf{4 a :} 0.59$ & $16.2 \%:$ pure $(\mathrm{Z})+62.5 \%: Z / E=1.0$ \\
\hline Cinchonidine 2b: 0.40 & $(Z)-4 \mathbf{b}: 0.59$ and $(E)-\mathbf{4 b}: 0.55$ & $18.5 \%$ : pure $(Z)+41.7 \%: Z / E=1.0$ \\
\hline
\end{tabular}

The geometric isomers $(E)$ - and $(Z)-\Delta^{3,10}$-isoquinine $4 \mathbf{a}$ as well as $(E)$ - and $(Z)-\Delta^{3,10}$-isocinchonidine $\mathbf{4 b}$ are visible on the TLC plates as separated spots $\left(R_{f}\right.$ values are done in the Table 3). The geometric isomer with the higher $R_{f}$ value can be partially isolated in pure form. We obtained from the crude $\mathbf{4 a}$ the sample of the single geometric isomer (Z)-4a $(16.2 \%)$ as the first fraction and next, an equimolar mixture of (Z/E)-4a isomers (62.5\% yield). From the crude $\mathbf{4 b}$, at first the pure isomer $(Z)-\mathbf{4 b}$ (its ${ }^{1} \mathrm{HNMR}$ spectrum is given on Fig. S10 in SM) was collected (yield 18.5\%), and next a $1: 1$ mixture of $(Z / E)-4 b$ in yield of $41.7 \%$.

Our experiments provide a new look at the reason of the differences in physicochemical properties of $\Delta^{3,10}$-isobases Cinchona alkaloids obtained long ago when not existed possibilities to control molecular composition, which is depended on methods of isomerisation process and also on method of products isolation. Their data in the old literature [18, 19 and ref. givens in 17] have been given probably for $\Delta^{3,10}$-isomeric alkaloids $\mathbf{3 a}, \mathbf{b}, \mathbf{4} \mathbf{a}, \mathbf{b}$ with different ratio of $(\mathrm{E}) /(\mathrm{Z})$ geometric isomers.

To the best of our knowledge, the results we obtained are similar to those presented in the literature for expensive heterogeneous (rhodium) and homogenous (ruthenium) catalysts used in this one-step reaction. $\Delta^{3,10}$-Isomers of natural Cinchona alkaloids will be applied in material and medicinal chemistry as reactants for preparation of organometallic catalysts and organocatalysts for asymmetric synthesis.

\section{Conclusion}

We elaborated the microwave-accelerated one-step catalytic isomerisation of the vinyl double bond, the side chain of Cinchona alkaloids, using inexpensive palladium solid supported catalyst, which was ineffective for this process under conventional heating. Mixture of ethylene glycol with hydrochloric acid was found as green reaction media. The reaction proved to be tolerant towards other functional groups present in natural molecules of Cinchona alkaloids. The conversion is depended on the kind of support, and on time and temperature of reaction.
We used the small analytical scale to choose the best catalyst and the reaction medium under controlled microwave irradiation. Next, the method was developed for the scale of 10 mmoles, which can be expanded to higher preparative scale. Especially good effects of almost complete conversion were obtained with $\mathrm{Pd} / \mathrm{BaSO}_{4}$ for quinidine 1a and quinine 2a transformations to appropriate $\Delta^{3,10}$-isomers: $(Z / E)$-3a and $(Z / E)-\mathbf{4 a}$, which were isolated by us in high yields $(80 \%$ and $79 \%$ ). The scope of application of our method was extended to the transformation of alkaloids without methoxy groups, $\mathbf{1 b}$ and $\mathbf{2 b}$, into (Z/E)-3b and (Z/E)-4b by using $\mathrm{Pd} /$ $\mathrm{Al}_{2} \mathrm{O}_{3}$ catalyst. Nevertheless, we developed two easy separation methods: the crystallisation with aqueous ethanol and the column chromatography, leading to $55-60 \%$ yields of pure $\Delta^{3,10}$-isobases $(Z / E)$-3b and $(Z / E)-\mathbf{4 b}$. Furthermore, the pure $(Z)-\Delta^{3,10}$-isomers $\mathbf{4 a}$ and $\mathbf{4 b}$ were isolated.

Diversity of the structure and stereochemistry of the natural Cinchona alkaloids results in divergence in conversion degree to $\Delta^{3,10}$-isomers with the each palladium supported catalyst. The fact that $\mathrm{Pd} / \mathrm{BaSO}_{4}$ is very effective in the cases of quinine and quinidine, but $\mathrm{Pd} / / \mathrm{Al}_{2} \mathrm{O}_{3}$ is the most effective for cinchonidine and cinchonine can be regarded as the difference in energy of the transition state in the isomerisation processes of both type of alkaloids. So, specific microwave interaction can be postulated in the formation and disintegration of the catalytic transition state: double bond of substrate-palladium-support in irradiated polar reaction mixture for each alkaloid. Our results show opportunity to enhance energy efficiency by the microwave irradiation in heterogenous catalytic reactions in polar reaction media.

\section{Experimental Section}

\subsection{General Information}

Commercial Cinchona alkaloids from Fluka were used. Catalysts and other reagents and solvents were purchased from commercial suppliers (Sigma-Aldrich) and used without further purification. Microwave heating at the controlled temperature was performed with SYNTHEWAVE 402 reactor 
(Prolabo, open system, external IR detector for temperature monitoring, connected with the software of computer for online temperature regulation). The course of reactions was monitored by thin-layer chromatography (aliquots were taken and extracted by ethyl ether in the presence of ammonia), which was carried out on $0.25 \mathrm{~mm}$ Merck silica gel (60 F254) plates on aluminum. Pure products were isolated by column chromatography with the Merck silica gel 60 (230-400 mesh). The column output was monitored with TLC. Melting points (uncorrected) were determined on the Bëthius apparatus. The optical rotations were measured on a Perkin Elmer 241 polarimeter. High resolution mass spectra were measured on AMD 604 Inectra $\mathrm{GmbH}$ spectrometer (EI) or on GC/MSQP 5050 Shimadzu spectrometer (ESI). IR spectra ( $\mathrm{KBr}$ pellets) were recorded on FT-IR MAGNA 769 (Nicolet). The ${ }^{1} \mathrm{H}$ and ${ }^{13} \mathrm{C}$ NMR spectra were recorded with VARIAN $400 \mathrm{MR}$ spectrometer $\left({ }^{1} \mathrm{H} ; 400 \mathrm{MHz},{ }^{13} \mathrm{C}\right.$ : $100 \mathrm{MHz})$. Chemical shifts are given relative to TMS $(\delta=0)$ in ppm and refer to residual solvent $\mathrm{CDCl}_{3}$ as internal standard. Examples of analytical ${ }^{1} \mathrm{H}$ NMR spectra are given in Supplementary Material (SM).

\subsection{General Procedure for Small Scale Catalytic Isomerisation of Cinchona Alkaloids by Method 1 and by Method 2 (Results in the Tables 1,2)}

To a quartz cylindrical vial (volume $10 \mathrm{~mL}$ ) was loaded with $0.5 \mathrm{mmol}$ of Cinchona alkaloid (162 $\mathrm{mg}$ 1a or $\mathbf{2 a}$ versus $147 \mathrm{mg}$ of $\mathbf{1 b}$ or $\mathbf{2 b}$ ), $0.75 \mathrm{~mL}$ of $50 \%$ ethanol (method 1) or $0.75 \mathrm{~mL}$ of $50 \%$ ethylene glycol (method 2), $0.15 \mathrm{ml}$ (1.8 mmol, $350 \% \mathrm{~mol}$ ) of concentrated $\mathrm{HCl}$ and $10 \mathrm{mg}$ $(1 \mathrm{mg}=0.009 \mathrm{mmol} \mathrm{Pd}, 1.8 \% \mathrm{~mol})$ of $10 \%$ palladium catalyst $\left(\mathrm{Pd} / \mathrm{Al}_{2} \mathrm{O}_{3}\right.$ or $\mathrm{Pd} / \mathrm{C}$ or $\left.\mathrm{Pd} / \mathrm{BaSO}_{4}\right)$. The reaction mixture was irradiated in the Synthewave 402, Prolabo microwave reactor (open system) at the programmed temperature $70{ }^{\circ} \mathrm{C}$ (method 1$)$ or $85^{\circ} \mathrm{C}(\operatorname{method} 2)$. The conversion of substrate was monitored by taking of micro-samples of the reaction mixtures regularly, in the interval of each $10 \mathrm{~min}$, which after extraction with diethyl ether in the presence of aqueous ammonia were analyzed by TLC (silica gel plates, 2-methoxyethanol, $R_{f}$ values are shown in the Table 3 ). The irradiation was stopped after $30 \mathrm{~min}$ or after $50 \mathrm{~min}$. The reaction mixture was filtered by Celite and added to the cold aqueous ammonia $(5 \mathrm{~mL})$. The white solid was filtered off, washed with water and dried. The obtained crude product was analyzed by ${ }^{1} \mathrm{H}$ NMR to determine of the conversion degree and the ratio of geometric isomers. The results of analysis are given in Table 1 (method 1$)$ and in Table 2 (method 2$)$. The examples of spectra of crude products are given in Supporting Material.

\subsection{Preparative Scale Isomerisation and Purification of Crude Products}

To a quartz cylindrical vial (volume $50 \mathrm{~mL}$ ) was added $10 \mathrm{mmol}$ of Cinchona alkaloid (3.24 g 1a or 2a vs $2.94 \mathrm{~g}$ of $\mathbf{1 b}$ or $\mathbf{2 b}), 15.0 \mathrm{~mL}$ of $50 \%$ ethylene glycol, $3.0 \mathrm{~mL} 36 \mathrm{mmol}$, $350 \%$ mol of concentrated $\mathrm{HCl}$ and $200 \mathrm{mg}$, of $10 \% \mathrm{Pd} /$ $\mathrm{BaSO}_{4}(20 \mathrm{mg}, 0.18 \mathrm{mmol} \mathrm{Pd}, 1.8 \% \mathrm{~mol})$. The reaction mixture was irradiated in the Synthewave 402 microwave reactor (open system) at the programmed temperature or $85^{\circ} \mathrm{C}$ for a period $50 \mathrm{~min}$. The reaction mixture was filtered by Celite and added to the excess of cold aqueous ammonia. The white solid was filtered off, washed with water and dried. Separation by column chromatography of $(Z / E)$ - $\Delta^{3,10}$-isomers from crude products was performed using $200 \mathrm{~g}$ of silica gel and a mixture of ethyl acetate:methanol in the ratio 20:1 as eluent.

\subsubsection{The Mixture of Geometric Isomers (Z/E)-(S)-[(2R,4S)-5-Ethylidenequinuclidin-2-yl] (6-methoxyquinolin-4-yl)methanol, (Z/E)-3a in the Ratio 4}

The crude $\Delta^{3,10}$-isoquinidine 3a $(3.20 \mathrm{~g}, 96.0 \%)$ was obtained according to entry 10 . Table 2 and its purity was determined by ${ }^{1} \mathrm{H}$ NMR spectroscopy (SM, Fig. S3): the conversion $98 \%$, the ratio $(Z / E)=(78: 20)$. The crude product was purified by column chromatography and the product as the mixture $\Delta^{3,10}$-isomer $(Z / E)$-3a in the ratio $4: 1$ was obtained as possessing the most higher $R_{f}$ value (Table 3 ). Yield $2.84 \mathrm{~g}, 88.0 \%$, mp $191.0-192.5^{\circ} \mathrm{C},[\alpha]_{\mathrm{D}}{ }^{22}+181.0^{\circ}$ (c1 in EtOH); \{lit, [13]: $\mathrm{mp} 178-180^{\circ} \mathrm{C},[\alpha]_{\mathrm{D}}{ }^{15}+193.2(\mathrm{c}$ 1 , EtOH) called as an apoquinidine methyl ether $\}.{ }^{1} \mathrm{H}$ NMR (400 MHz, $\left.\mathrm{CDCl}_{3}, \delta, \mathrm{ppm}\right): 8.68\left(\mathrm{~d}, J=4.4 \mathrm{~Hz}, 1 \mathrm{H}, 2^{\prime}-\mathrm{H}\right)$, $7.90\left(\mathrm{~d}, J=8.8 \mathrm{~Hz}, 1 \mathrm{H}, 8^{\prime}-\mathrm{H}\right), 7.54$ (d, $\left.J=4.4 \mathrm{~Hz}, 1 \mathrm{H}, 3^{\prime}-\mathrm{H}\right)$, 7.23 (dd, $\left.J=8.9,2.4 \mathrm{~Hz}, 1 \mathrm{H}, 7^{\prime}-\mathrm{H}\right), 7.13$ (d, $J=2.4 \mathrm{~Hz}$, $\left.1 \mathrm{H}, 5^{\prime}-\mathrm{H}\right), 5.97$ (br s, $\left.1 \mathrm{H}, 9-\mathrm{H}\right), 5.33-5.27(\mathrm{~m}, 0.8 \mathrm{H}, 10-\mathrm{H}$ of $(Z)-3 a), 5.27-5.18(\mathrm{~m}, 0.2 \mathrm{H} 10-\mathrm{H}$ of $(E)-3 \mathbf{a}), 4.43(\mathrm{~d}$, $J=15.6 \mathrm{~Hz}, 1 \mathrm{H}, 2-\mathrm{H}), 3.88$ (s, $3 \mathrm{H}, \mathrm{MeO}), 3.50$ (d, $J=15.6$, $1 \mathrm{H}, 2-\mathrm{H}), 3.28(\mathrm{~m}, 1 \mathrm{H}, 8-\mathrm{H}), 3.06(\mathrm{~m}, 1 \mathrm{H}, 6-\mathrm{H}) 2,87(\mathrm{~m}, 1 \mathrm{H}$, 6-H), 2.44 (br s, 1H, 4-H), 2.06 (m, 1H, 5-H), 1.68 (m, 2H, 5-H, 7-H), $1.62\left(\mathrm{~d}, J=6.4 \mathrm{~Hz}, 0.6 \mathrm{H}(E)-\mathrm{CH}_{3} \mathrm{CH}=\right), 1.54$ $\left(\mathrm{d}, J=6.4 \mathrm{~Hz}, 2.4 \mathrm{H}(\mathrm{Z})-\mathrm{CH}_{3} \mathrm{CH}=\right), 1.40(\mathrm{~m}, 1 \mathrm{H}, 7-\mathrm{H}),{ }^{13} \mathrm{C}$ NMR (100 MHz, $\mathrm{CDCl}_{3}, \delta$, ppm): $157.4\left(\mathrm{C}^{\prime}\right), 148.2\left(\mathrm{C}^{\prime}\right)$, $147.3\left(\mathrm{C} 2^{\prime}\right), 144.0\left(\mathrm{C}^{\prime}\right), 141.8$ (C3), $131.3\left(\mathrm{C}^{\prime}\right), 126.5$ (C10'), 121.5 (C3'), 118.6 (C7'), 113.1 (C10), 101.3 (C5'), 71.4 (C9), 59.6 (C8), 55.6 (MeO), $51.2(\mathrm{C} 2), 50.0(\mathrm{C} 6), 33.5$ (C4), 22.5 (C5), 22.3 (C7), 12.3 (C11); IR (KBr), $\mathrm{cm}^{-1}$ : 3419. 3160, 2936, 1509, 1432, 1366, 1240, 1120, 1096, 1077, 1054, 1027; MS (EI), m/e (\%): $324\left(\mathrm{M}^{+}, 100 \%\right), 309$ (16), 189 (45), 136 (95), 108 (20); HRMS (EI): founded 324.18372, for $\mathrm{M}^{+}$, calculated for $\mathrm{C}_{20} \mathrm{H}_{24} \mathrm{~N}_{2} \mathrm{O}_{2}: 324.18378$. 


\subsubsection{Pure (Z)-4a and the Mixture 1:1 (Z/E)-4a}

The crude $\Delta^{3,10}$-isoquinine $4 \mathbf{a}(3.08 \mathrm{~g}, 95.0 \%)$ was obtained according to the entry 12 , Table 2 and its purity was determined by ${ }^{1} \mathrm{H}$ NMR spectrum (Fig. S6: conversion $96 \%$, $Z / E=6.1 / 3.5)$. The crude product was purified by column chromatography. At the beginning the pure $\Delta^{3,10}$-isomer $(Z)$ 4a was obtained $\left\{0.52 \mathrm{~g}, 16.2 \%, \mathrm{mp} 180-181{ }^{\circ} \mathrm{C},[\alpha]_{\mathrm{D}}{ }^{22}\right.$ $-158.6^{\circ}(\mathrm{c} 1$ in $\left.\mathrm{EtOH})\right\}$ and next the mixture $1: 1$ of $(Z / E)$ 4a $\Delta^{3,10}$-isomers was collected: yield $0.51 \mathrm{~g}, 62.5 \%$, mp $184-185{ }^{\circ} \mathrm{C},[\alpha]_{\mathrm{D}}{ }^{22}-172.4^{\circ}$ (c1 in EtOH). Lit [18, 19]: $\beta$-isoquinine or apoquinine methyl ether, mp $183-185^{\circ} \mathrm{C}$, $[\alpha]_{\mathrm{D}}^{15}-201.9^{\circ}(\mathrm{c} 1 \mathrm{in} \mathrm{EtOH})$ and $\alpha$-isoquinine or isoapoquinine methyl ether: $\mathrm{mp} 192-194[\alpha]_{\mathrm{D}}^{22}-253.4^{\circ}$ (c 0.811, EtOH). Spectral data for the $\Delta^{3,10}$-isoquinine as Z:E mixture in ratio $1: 1(\boldsymbol{Z} / \boldsymbol{E})-4 \mathrm{a},(\boldsymbol{Z} / \boldsymbol{E})-\boldsymbol{R}-[(2 S, 4 S)-$,5 -ethylidenequinuclidin-2-yl](6methoxyquinolin-4-yl)methanol: ${ }^{1} \mathrm{H}$ NMR (400 MHz, $\left.\mathrm{CDCl}_{3}, \delta, \mathrm{ppm}\right): 8.71$ (d, J=4.4 Hz, $1 \mathrm{H}$, $\left.2^{\prime}-\mathrm{H}\right), 7.92$ (d, $\left.J=9.2 \mathrm{~Hz}, 1 \mathrm{H}, 8^{\prime}-\mathrm{H}\right), 7.60$ (d, $J=4.4 \mathrm{~Hz}$, $\left.1 \mathrm{H}, 3^{\prime}-\mathrm{H}\right), 7.24$ (d, $\left.J=2.4 \mathrm{~Hz}, 1 \mathrm{H}, 5^{\prime}-\mathrm{H}\right), 7.14$ (dd, $J=9.2$, $2.4 \mathrm{~Hz}, 1 \mathrm{H}, 7^{\prime}-\mathrm{H}$ ), 5.89 (br s, 1H, 9-H), 5.27-5.20 (m, 0,5 H, 10-H from (Z)-4a), 5.20-5.13 (m, 0.5 H, 10-H from $(E)-4 a)$, 3,84 and $3.82(2 \times s$ s, $\mathrm{MeO}$ from $(Z / E)-4 a), 3.60-3.45(\mathrm{~m}$, 2H, 2-H), 3.24-3.16 (m, 1H, 8-H), 2.94-2.80 (m, 2H, 6-H), 2.42-2.38 (m, 1H, 4-H), 2.08-2.00 (m, 1H, 5-H), 1.92-1.84 (m, 1H, 7-H), 1.70-1.60 (m, 1H, 5-H), 1.52 (d, J=7.6 Hz, 1,5 H, 11-H from (Z)-4a), 1.45 (d, $J=5.8 \mathrm{~Hz}, 1.5 \mathrm{H}, 11-\mathrm{H}$ from $(E)-4 a), 1.42-138(\mathrm{~m}, 1 \mathrm{H}, 7-\mathrm{H}) ;{ }^{13} \mathrm{C}$ NMR $(100 \mathrm{MHz}$, $\left.\mathrm{CDCl}_{3}, \delta, \mathrm{ppm}\right): 157.4\left(\mathrm{C}^{\prime}\right), 147.9\left(\mathrm{C}^{\prime}\right), 147.2\left(\mathrm{C}^{\prime}\right)$, 143.2 (C9'), 139.1 (C3), 131.1 (C8'), $126.4\left(\mathrm{C} 10^{\prime}\right), 121.3$ (C3'), 118.5 (C7'), 113.1 (C10), 101.3 (C5'), 70.9 (C9), 60.8 (C8), 56.5 (C2), 55.7 (MeO), 44.0 (C6), 33.1 (C4), 27.4 (C5, C7), 12.3 (C11); IR (KBr), cm cm $^{-1} 200$ br, 2990, 1622, 1591, 1566, 1511, 1459, 1384, 1340, 1262, 1190, 1171, 1124, 1090, 1079, 1035. MS (EI), m/e (\%): $324\left(\mathrm{M}^{+}, 85 \%\right)$, 309 (18), 189 (75), 136 (100), 108 (25); HRMS (EI): $\mathrm{M}^{+}$ founded 324.18381, calculated for $\mathrm{C}_{20} \mathrm{H}_{24} \mathrm{~N}_{2} \mathrm{O}_{2} 324.18378$.

\subsubsection{The Mixture of Geometric Isomers (Z/E)-3b in the Ratio 4.5}

The crude $\Delta^{3,10}$-isocinchonine $\mathbf{3 b}$ was obtained by method 2 from $10 \mathrm{mmol}(2.94 \mathrm{~g}) \mathbf{1 b}$ with $200 \mathrm{mg} \mathrm{Pd} / \mathrm{Al}_{2} \mathrm{O}_{3}$ in yield 95\%. Its analysis by ${ }^{1} \mathrm{H}$ NMR (Fig. S7 in SM) was showed $70 \%$ containing of $(Z / E)-3 \mathbf{b}$ in the ratio 2.5 and $20 \%$ of unconverted substrate $\mathbf{1 b}$. The crude product $(2.80 \mathrm{~g})$ was purified by column chromatography $1.60 \mathrm{~g}(55.0 \%)$ of the pure $\Delta^{3,10}$-isomer $(Z / E)-3 \mathbf{b}$ in the ratio $4.5: 1$ was collected $\left({ }^{1} \mathrm{H}\right.$ NMR spectrum see Fig. S8 in SM), mp $210.0-212.0^{\circ} \mathrm{C}$, $[\alpha]_{\mathrm{D}}^{22}+157.8^{\circ}(\mathrm{c} 1$ in EtOH$)$. Literature data for apocinchonine $[22,23]:: \operatorname{mp} 214-216^{\circ} \mathrm{C},[\alpha]_{\mathrm{D}}^{22}+158.8^{\circ}$ (c0.510 in EtOH).Spectral data for $(Z / E)-(S)-[(2 R, 4 S)-5$-ethylidenequinuclidin-2-yl](quinolin-4-yl)methanol, $(Z / E)-3 b$ in the ratio 4.5:1: ${ }^{1} \mathrm{H}$ NMR (see, Fig. $\mathrm{S} 8$ in $\mathrm{SM}$ ): (400 MHz, $\left.\mathrm{CDCl}_{3} \delta, \mathrm{ppm}\right): 8.75\left(\mathrm{~d}, J=4.8 \mathrm{~Hz}, 1 \mathrm{H}, 2^{\prime}-\mathrm{H}\right), 8.05$ (d, $\left.J=8.3 \mathrm{~Hz}, 1 \mathrm{H}, 8^{\prime}-\mathrm{H}\right), 7.84$ (d, $\left.J=8.6 \mathrm{~Hz}, 1 \mathrm{H}, 5^{\prime}-\mathrm{H}\right), 7.58$ (t, $\left.J=8.3 \mathrm{~Hz}, 1 \mathrm{H}, 7^{\prime}-\mathrm{H}\right), 7.56\left(\mathrm{~d}, J=4.8 \mathrm{~Hz}, 1 \mathrm{H}, 3^{\prime}-\mathrm{H}\right)$, $7.20\left(\mathrm{t}, J=8.3 \mathrm{~Hz}, 1 \mathrm{H}, 6^{\prime}-\mathrm{H}\right), 5.71$ and $5.68(\mathrm{~d}, J=3.6 \mathrm{~Hz}$ and d, $J=4.0 \mathrm{~Hz}, \Sigma 1 \mathrm{H}, 9-\mathrm{H}$ in $Z / E-3 b), 5.34$ (br s, $1 \mathrm{H}$, $\mathrm{OH}), 5.23-5.15$ (m, 0,82 H, 10-H in (Z)-3b), 5.15-5.08 (m, $0.18 \mathrm{H}, 10-\mathrm{H}$ in $(E)-3 \mathbf{b}), 4.14$ (d, $J=16,4 \mathrm{~Hz}, 1 \mathrm{H}, 2-\mathrm{H})$, 3.21 (d, $J=16,4 \mathrm{~Hz}, 1 \mathrm{H}, 2-\mathrm{H}), 3.14-296(\mathrm{~m}, 1 \mathrm{H}, 8-\mathrm{H})$, 2.88-2.78 (m, 2H, 6-H), 2.72-2.62 (m, 1H, 6-H), 2.32 (br s, $1 \mathrm{H}, 4-\mathrm{H}), 2.00-1.92(\mathrm{~m}, 1 \mathrm{H}, 5-\mathrm{H}), 1.61-1.45(\mathrm{~m}, \Sigma 5 \mathrm{H}=\mathrm{m}$, $2 \mathrm{H}$, from $5-\mathrm{H}$ and $7-\mathrm{H}+2 \times \mathrm{d}, 3 \mathrm{H} 10-\mathrm{H}_{3}$ at 1.58 and 1.48 , $J=6.4 \mathrm{~Hz}$, for $\underline{\mathrm{H}}_{3} \underline{\mathrm{C}}-\mathrm{CH}=$ in $\left.(Z / E)-3 \mathbf{b}\right), 1.41-133(\mathrm{~m}, 1 \mathrm{H}$, $7-\mathrm{H}) ;{ }^{13} \mathrm{C}$ NMR $\left(100 \mathrm{MHz}, \mathrm{CDCl}_{3}, \delta, \mathrm{ppm}\right): 150.4,149.7$, $148.3,141.9,130.5,129.3,126.8,125.8,123.2,118.6$, $113.4,72.0,60.2,51.4,51.1,33.7,27.7,27,5,12.6$; IR (KBr, $\mathrm{cm}^{-1}$ ); 3416 (br), 3068, 2917, 2975, 2716 (br), 1620, 1590, 1569, 1509, 1459, 1383, 1333, 1299, 1235, 1209, 1168, 1119, 1099, 1054, 1028, 993, 951, 885, 864, 832, 798, 759, 689; HR MS (ESI) $[\mathrm{M}+\mathrm{H}]^{+}$: founded: 295.1811, calculated for $\mathrm{C}_{19} \mathrm{H}_{23} \mathrm{~N}_{2} \mathrm{O}: 295.1810$.

\subsubsection{Pure (Z)-4b and Mixture 1:1 (Z/E)-4b}

The crude $\Delta^{3,10}$-isocinchonidine $\mathbf{4 b}$ was obtained by method 2 from $10 \mathrm{mmol}(2.94 \mathrm{~g}) \mathbf{2 b}$ with $200 \mathrm{mg} \mathrm{Pd} / \mathrm{Al}_{2} \mathrm{O}_{3}$ in yield $92 \%$. Its analysis by ${ }^{1} \mathrm{H}$ NMR (spectrum, Fig. S9 in SM) was showed $65 \%$ containing of $(Z / E)-4 b$ in the ratio $42: 23$ and $35 \%$ of unconverted substrate $\mathbf{2 b}$. The crude product (2.68 g) was purified by column chromatography. At the beginning the pure $\Delta^{3,10}$-isomer $(Z)-4 b 0.56 \mathrm{~g}$, $(18.5 \%)$ was separated $\left({ }^{1} \mathrm{H}\right.$ NMR spectrum-Fig. S10 in SM), m.p. $230.0-232.0{ }^{\circ} \mathrm{C},[\alpha]_{\mathrm{D}}^{22}-95.5^{\circ}$ (c1 in EtOH), and next was collected $1.24 \mathrm{~g},(41.7 \%)$ of the mixture $1: 1(Z / E)-\mathbf{4 b}$ $\Delta^{3,10}$-isomers $[\alpha]_{\mathrm{D}}^{22}-172.4^{\circ}(\mathrm{c} 1$ in EtOH$)$. Spectral data for pure $(R)-[(2 S, 4 S, Z)-5$-ethylidenequinuclidin-2-yl] (quinolin-4-yl)methanol, (Z)-4b: ${ }^{1} \mathrm{H}$ NMR (400 MHz, $\left.\mathrm{CDCl}_{3}, \delta, \mathrm{ppm}\right): 8.87$ (d, J=4.6 Hz, 1H, 2'-H), 8.09 (dd, $\left.J=7.8,1.2 \mathrm{~Hz}, 1 \mathrm{H}, 6^{\prime}-\mathrm{H}\right), 7.99$ (dd, $\left.J=8.2,1.2 \mathrm{~Hz}, 8^{\prime}-\mathrm{H}\right)$, 7.66 (ddd $\left.J=8.2,7.0,1.2 \mathrm{~Hz}, 1 \mathrm{H}, 7^{\prime}-\mathrm{H}\right), 7.59$ (d, $J=4.6 \mathrm{~Hz}$, 1H, 3'-H), 7.43 (ddd, J=7.8. 7.0, 1.2 Hz, 1H, 6'-H), 5.80 $(\mathrm{d}, J=3.2 \mathrm{~Hz}, 1 \mathrm{H}, 9-\mathrm{H}), 5.18$ (qt, $J=6.8,2.4 \mathrm{~Hz}, 1 \mathrm{H}$, 10-H), 3.67-3.58 (m, 1H, 8-H), 3.50 (d, J=16.4 Hz, 1H, 2-H), 3.37 (d, $J=16.4 \mathrm{~Hz}, 1 \mathrm{H}, 2-\mathrm{H}), 3.14$ (ddd, $J=14.4$, 12.2. $4.8 \mathrm{~Hz}, 1 \mathrm{H}, 6-\beta-\mathrm{H}), 2,74$ (ddd, $J=12.2,8.7,4.8 \mathrm{~Hz}$, 6- $\alpha-\mathrm{H}), 2.35$ (d, $J=2.4 \mathrm{~Hz}, 1 \mathrm{H}, 4-\mathrm{H}), 1.97$ (ddd, $J=12.7$, 8.7, $1.5 \mathrm{~Hz}, 5-\alpha-\mathrm{H}), 1.79$ (tt, $J=11,3,4.3 \mathrm{~Hz}, 1 \mathrm{H}, 7-\beta-\mathrm{H})$, 1.64-1.54 (m, 1H, 5- $\beta-\mathrm{H}), 1.48-1.38(\mathrm{~m}, 1 \mathrm{H}, 7-\alpha-\mathrm{H}), 1.42$ $(\mathrm{d}, 3 \mathrm{H}, J=6.8 \mathrm{~Hz}, 11-\mathrm{H}) ;{ }^{13} \mathrm{C} \mathrm{NMR},\left(100 \mathrm{MHz}, \mathrm{CDCl}_{3}, \delta\right.$, ppm): 150.8, 150.5, 150.0, 149.1, 148.5, 130.7, 129.4, 127.0, 123.3, 118.5, 115.3, 72.1, 61.5, 57.0, 44.4, 33.6, 26.1, 25.8, 13.1; IR ( $\mathrm{KBr}, \mathrm{cm}^{-1}$ ); 3428 (br), 3018, 2929, 2859, 2715 (br), 1622, 1590, 1569, 1508, 1446, 1381, 1345, 1302, 1236, 
$1160,1122,1093,1079,1031,977,941,880,806,790,759$, 640; HR MS (ESI) $[\mathrm{M}+\mathrm{H}]^{+}$founded: 295.1813, calculated for $\mathrm{C}_{19} \mathrm{H}_{23} \mathrm{~N}_{2} \mathrm{O}: 295.1810$.

Open Access This article is distributed under the terms of the Creative Commons Attribution 4.0 International License (http://creativecommons.org/licenses/by/4.0/), which permits unrestricted use, distribution, and reproduction in any medium, provided you give appropriate credit to the original author(s) and the source, provide a link to the Creative Commons license, and indicate if changes were made.

\section{References}

1. Verpoorte R (1994) In: Saxton JE (ed) Monoterpenoid indole alkaloids, supplement to vol 25 part 4. Wiley, Chichester, pp 647-687

2. Hoffmann H, Martin R, Frackenpohl J (2004) Recent advances in cinchona alkaloid chemistry. Eur J Org Chem 4293-4312

3. Hisaki I, Hiraishi E, Sasaki T, Orita H, Tsuzuki S, Tohnai N, Miyata M (2012) Crystal structure of quinine: the effects of vinyl and methoxy groups on molecular assemblies of cinchona alkaloids cannot be ignored. Chem Asian J 7:2607-2614

4. Milberg P, Tegelkamp R, Osada N, Schimpf R, Wolpert C, Breithardt $G$ et al (2007) Reduction of dispersion of repolarization and prolongation of postrepolarization refractoriness explain the antiarrhythmic effects of quinidine in a model of short QT syndrome. J Cardiovasc Electrophysiol 18,:658-664

5. Karle JM, Bhattacharjee AK (1999) Stereoelectronic features of the cinchona alkaloids determine their differential antimalarial activity. Bioorg Med Chem 7:1769-1774

6. Song ChE (ed) (2009) Cinchona alkaloids in synthesis and catalysis: ligands, immobilization, and organocatalysis. Wiley-VCH, Weinchein

7. Kaczorowski T, Justyniak I, Lipińska T, Lipkowski J, Lewiński J (2009) Metal complexes of cinchonine as chiral building blocks: a strategy for the construction of nanotubular architectures and helical coordination polymers. J Am Chem Soc 131:5393-5395

8. Lewiński J, Kaczorowski T, Prochowicz D, Lipińska T, Justyniak I, Kaszkur Z, Lipkowski J (2010) Cinchona alkaloid-metal complexes: noncovalent porous materials with unique gas separation properties. Angew Chem Int Ed Engl 49:7035-7039

9. Exner C, Pfaltz A, Studer M, Blaser H-U (2003) Heterogeneous enantioselective hydrogenation of activated ketones catalyzed by modified Pt-catalysts: a systematic structure-selectivity study. Adv Synth Catal 345:1253-1260

10. Cederbaum F, Lamberth C, Malan C, Naud F, Spindler F, Studer M, Blaser H-U (2004) Synthesis of substituted mandelic acid derivatives via enantioselective hydrogenation: homogeneous versus heterogeneous catalysis. Adv Synth Catal 346:842-848

11. Balázsik K, Martinek TA, Bucsi I, Szollosi G, Fogassy G, Bartok M, Olah GA (2007) A new rigid cinchona modified ( $\alpha$-IQ) platinum catalyst for the enantioselective hydrogenation of activated ketones: data to the origin of enantioselection. J Mol Catal A 272:265-274

12. Nakano A, Ushiyama M, Iwabuchi Y, Hatakeyama S (2005) Synthesis of an enantiocomplementary catalyst of $\beta$-isocupreidine $(\beta-\mathrm{ICD})$ from quinine. Adv Synth Catal 347:1790-1796

13. Carroll FI, Abraham P, Gaetano K;. Mascarella SW, Wohl RA, Lind J, Petzoldt K (1991) (3S)-3-hydroxyquinidine, the major biotransformation product of quinidine. Synthesis and conformational studies. X-ray molecular structure of (3S)-3-hydroxyquinidine, methanesuiphonate. J Chem Soc Perkin Trans I 3017-3026
14. von Riesen C, Hoffmann H. M. R. (1996) A tricyclic dehydrorubanone and new isomers of the major quinidine metabolite. Chem Eur J 2:680-684

15. Frackenpohl J, Langer P, Hoffmann H. M. R. (1998) 1,2-Carbonyl transposition of a protected rubanone: stereoselective synthesis of bicyclic and tricyclic lactams derived from quinidine. Helv Chim Acta 81:1429-1438

16. Langer P, Hoffmann H.M.R. (1997) Diastereocontrol of nucleophilic attack of the rubanone carbonyl group via remote siloxy tether. Establishing the natural configuration at carbon C-3 of Cinchona alkaloids. Tetrahedron 53:9145-9158

17. Turner RR, Woodward RR (1953) In: Manske RHF, Holmes HL (eds) The alkaloids, vol 3. Academic Press, New York, pp 1-64

18. Henry TA, Solomon W, Gibbs EM (1935) Modified cinchona alkaloids. Part II. The action of sulphuric acid on quinine and quinidine. J Chem Soc 1935:966-971

19. Henry TA, Solomon W, Gibbs EM (1937) Modified cinchona alkaloids. Part IV. Constitution. J Chem Soc 1937:592-601

20. Thiel J, Fiedorow P (1997) An NMR and molecular mechanics structural study on some ethereal and $\Delta^{3,10}$-isomers of cinchona alkaloids. J Mol Struct 405:219-230

21. Thiel J, Katrusiak A (2002) Asymmetric conversions of 10-bromo-10,11-dihydroquinines into 8-oxa-1-azabicyclo [4.3.0] nonane derivatives and related compounds. Tetrahedron Asymmetry 13:47-57

22. Cheung AP, Benitez A, Lim P (1968) Isolation and identification of contaminants found in commercial dihydroquinine. J Org Chem 33:3005-3006

23. Portlock DE, Naskar D, West L, Seibel WL, Gu T, Krauss H, Peng XS, Dybas PM, Soyke EG, Ashton SB, Burton J (2003) Positional isomerization of quinine and quinidine via rhodium on alumina catalysis: practical one-step synthesis of $\Delta^{3,10}$-isoquinine and $\Delta^{3,10}$-isoquinidine. Tetragedron Lett 44:5365-5368

24. Loupy A (ed) (2006) In Microwaves in organic synthesis, Chap. 13. Wiley-VCH, Weinchein, pp 615-652

25. Toukoniitty B, Mikkola JP, Murzin DY, Salmi T (2005) Utilizationof electromagnetic and acoustic irradiation in enhancing heterogeneous catalytic reactions. Appl Catal A 279:1-22

26. Strauss CR, Rooney DW (2010) Accounting for clean, fast and high yielding reactions under microwave conditions. Green Chem 2:1340-1344

27. Ji T, Tu R, Mu LW, Lu XH, Zhu JH (2017) Enhancing energy efficiency in saccharide-HMF conversion with core/shell structured microwave responsive catalysts. ACS Sustain Chem Eng 5:4352-4435

28. Lipinska T (2004) Microwave-induced solid-supported Fischer indolization, a key step in the total synthesis of the sempervirine type methoxy analogues. Tetrahedron Lett 45:8831-8834

29. Lipinska TM, Czarnocki SJ (2006) A new approach to difficult Fischer synthesis: the use of zinc chloride catalyst in triethylene glycol under controlled microwave irradiation. Org Lett $8: 367-370$

30. .Karczmarzyk Z, Lipińska TM, Wysocki W, Denisiuk M, Piechocka K (2011) Tosyl esters of cinchonidine and cinchonine alkaloids: the structure-reactivity relationship in the hydrolysis to 9-epibases. Acta Crystallogr C 67:0346-o349

31. Lipińska TM, Piechocka K, Denisiuk M, Chmiel B, SkórskaStania A (2012) Structure-reactivity study of $O$-tosyl Cinchona alkaloids in their new synthesis and in hydrolysis to 9-epibases. Unexpected formation of cinchonicine enol tosylate accelerated by microwave activation. Arkivoc 6:264-280

32. Lipińska TM, Radzikowska N, Swędra N (2012) Patent PL 212263 B1 